\title{
A PILOT STUDY ON THE USE OF ELECTRICAL BIOIMPEDANCE SYSTEM AS A PRIMARY METHOD FOR BREAST CANCER SCREENING
}

\author{
Islam G. Ali \\ Department of Medical Biophysics \\ Medical Research Institute, \\ Alexandria University, Alexandria, Egypt.
}

\begin{abstract}
Electrical Bio-impedance Tomography (EBT) is a homemade non-invasive system designed to image breasts in the geometry of mammogram through applying an alternating-current (AC) and measuring the voltage distribution that result, and using computational methods to reconstruct an image of the breast conductivity that corresponds to breast pathology. In this study, 126 patients were examined with EBT and compared these images to Xray Mammography (MG). Using the visual criterion, the sensitivity of EBT in diagnosing different breast pathology was found to be less sensitive compared to mammography with no significant difference. EBT could be used as an adjunct to MG for breast cancer screening.
\end{abstract}

Keywords-Electrical Bioimpedance Tomography, X-ray Mammography, Breast electrical conductivity, Breast tissue classification

\section{INTRODUCTION}

Breast cancer is one of the most frequently diagnosed cancer in females worldwide and the rates are increasing [1] and it is largely attributed to aging of the population [2]. The breast cancer accounts for 30-40\% of all the cancers in women all over the world [3]. According to World Health Organization, more than $30 \%$ of cancer deaths can be prevented [4]. In general, the earlier the cancer is detected and treated, the better the chance for survival [5]. There are two methods for detection of malignancies of breast: first self-observation of early signs of cancer and tumors and seeking prompt medical attention, second screening programs campaigns to detect early cancer or pre-cancer stage before signs recognition [6]. In the past recent years, mortality has been decreased significantly due to screening by medical imaging modalities [7]. At present, X-ray mammography is the gold standard modality for breast cancer detection and screening [8], although mammography has high sensitivity and specificity within the fatty breast and in the detection of microcalcifications, it has some multiple shortcomings according to the Breast Cancer Detection Demonstration Project (BCDDP) [9, 10], mammography is particularly defenseless at missing malignancies in more youthful ladies with denser breast tissue. After 10 sessions, a woman has a

\author{
Tarek. Y. Aref \\ Department of Radiology \\ Medical Research Institute, \\ Alexandria University, Alexandria, Egypt.
}

cumulative probability of $49.1 \%$ of undergoing an unnecessary biopsy, and 70-80\% of the women who undergo biopsies due to their mammographic findings have benign lesions. Since mammography cause cumulative $\mathrm{x}$-ray exposure and it is hard to use with dense breast tissue (noticeable in more younger ladies), mammography is fundamentally prescribed for women over age 40 years of age [11]. Numerous ladies evade mammograms since they discover the breast pressure awkward and in certain cases painful. Mammography has a high number of false positive results, many women must undergo the psychological trauma, physical scarring, and financial hardship of unnecessary biopsies [12]. Instead of using X-rays to detect malignancies, another possibility is to use electricity to accomplish the same goal. Consequently, the new technology electrical bioimpedance tomography (EBT) which is a relatively new imaging method that has evolved over the past 20 years is recommended by Hope et al. (2004), which is a noninvasive procedure using electrical bioimpedance to image the human breast [13]. This scanning device is portable and does not emit any ionizing radiation thus it can be done on pregnant women by means of no age limit and not expensive [14]. The value of EBT technique is based on the variation of electrical storage potential values for both normal and pathological tissues. These variations allow to construct an image of conductivity and permittivity of the breast tissue. Previous experimental studies with EBT have shown that significant changes occur in the electrical properties of breast cancer tissue compared to the surronding normal tissue $[15,16]$. Some evidence has been found that malignant breast tumours have lower electrical impedance than surrounding normal tissues $[15,16]$. This observation has led to the proposal that electrical bioimpedance could be used as an indicator for breast cancer detection $[19,20,21]$. Using EBT system, is radiation free, and since it is portable, the screening can be done virtually anywhere. No materials like gel or ECG spray are required for scanning procedure. The research goal of this paper is to study the capability of the use of EBT as a dependable technique for breast cancer screening and diagnosis in comparing to X-ray mammography [22]. 


\section{International Journal of Engineering Applied Sciences and Technology, 2020 \\ Vol. 4, Issue 10, ISSN No. 2455-2143, Pages 1-4 \\ Published Online February 2020 in IJEAST (http://www.ijeast.com)}

\section{EXPERIMENTAL METHOD}

\section{A. EBT System Overview -}

This device consists of an array of 64 stainless steel electrodes (8x8) array with $10 \mathrm{~mm}$ diameter spaced by $5 \mathrm{~mm}$ fabricated on a printed circuit board and embedded in a Plexiglas plate, Figure [1] and uses small electrical pulses $(0.4$ $\mathrm{mA}, 125 \mathrm{kHz})$ for the breast examination. These electrodes array connected to the main unit which consists of multi frequency alternating current (AC) voltage source, Microcontroller, Multiplexers, Analog to Digital Converter (ADC), divider circuit, peak detector system, and computer for running software, A schematic diagram for EBT system is shown in Figure [2]. The procedure continues for each electrode, measurements are taken within 30 seconds. The received data is reconstructed into a tomographic conductivity images of the breast that analyzed and diagnosed for each patient and compared to the corresponding X-ray mammographic images for the same patient Figure [3].

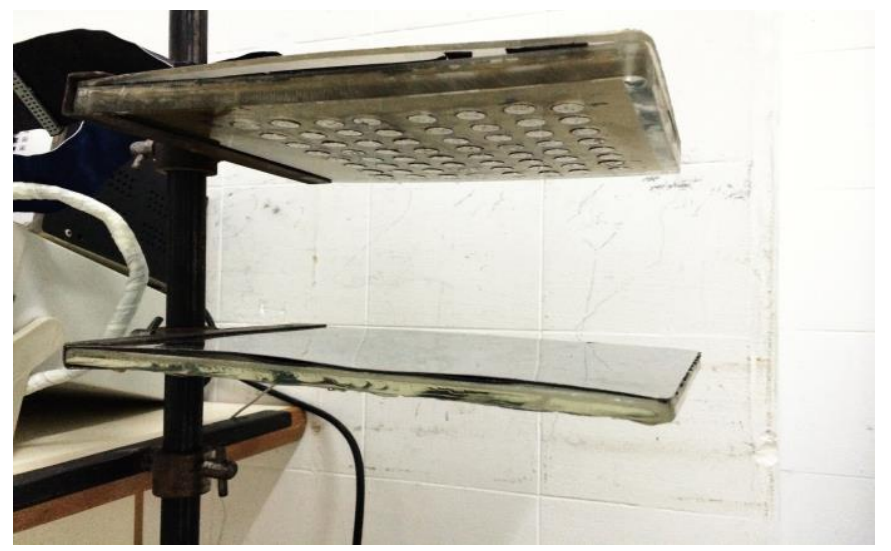

Fig. 1. Plexiglas plate containing embedded 64 electrodes for breast tissue electrical bioimpedance meaurements

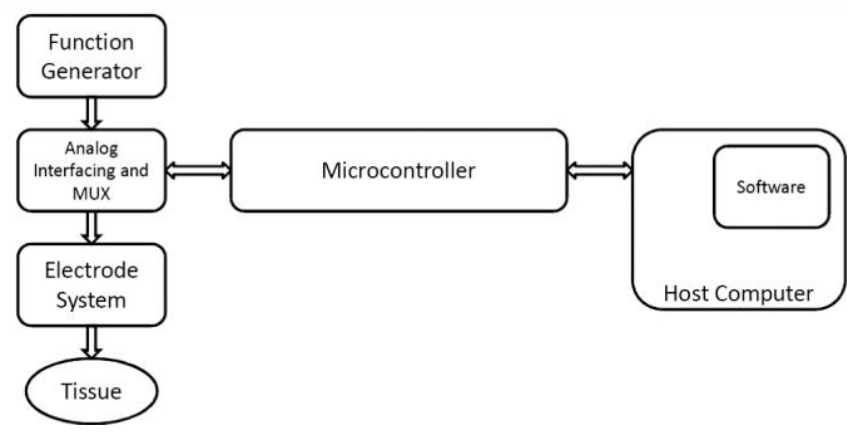

Fig. 2. A schematic diagram for EBT system hardware.

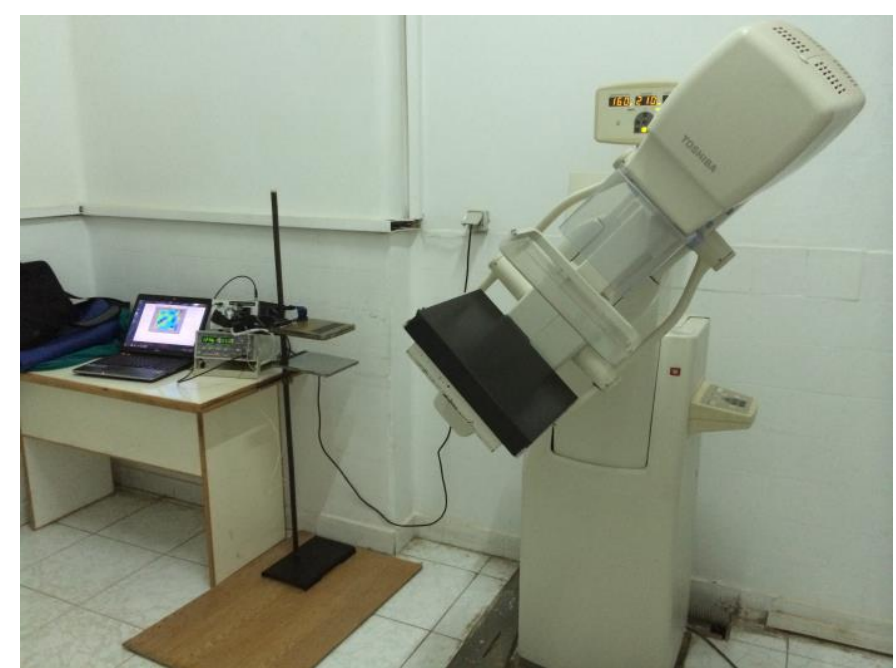

Fig. 3. X-ray Mamographic machine in adjacent to EBT system

\section{B. Breast Examination -}

In this study a total of 126 patients presenting with various breast complaints with confirmed diagnosis, 54 of them were normal cases, 24 were benign tumor cases, and 48 were cancer cases. All patients were examined using X-ray mammography (MG), and Electrical Bioimpedance Tomography (EBT) system. All the imaging procedures done at Department of Radiology, Medical Research Institute, Alexandria University, Egypt. after all the volunteers completed the necessary consent forms.

\section{RESUlt AND Discussion}

The study was conducted to determine the diagnostic efficiency of Electrical biompedance Tomography (EBT) system as compared to X-ray Mammography (MG) in imaging the breast as shown in Figure [4], an example case for the images of both MG and EBT in cranio-caudal position for right breast of 47-year old woman and has BMI $23.2 \mathrm{Kg} / \mathrm{m}^{2}$. This patient was diagnosed as normal case using the visual criterion, since no inhomogeneities were observed. Another example case in shown in Figure [5] the images for left breast of 56-year old woman and has BMI $23 \mathrm{Kg} / \mathrm{m}^{2}$, this patient was diagnosed as abnormal case using the visual criterion, since the marked area refer to central breast mass surrounded by tissue infiltration.
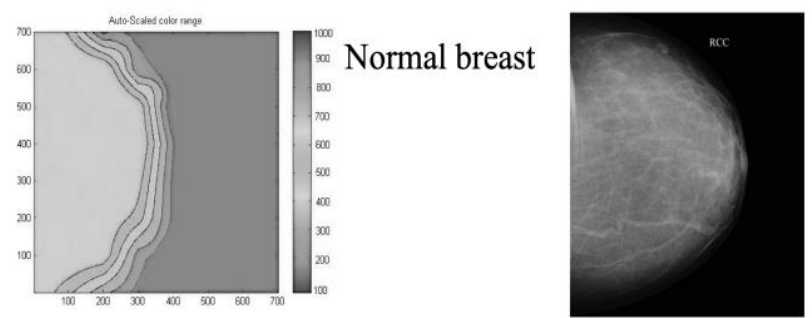

Fig. 4. Images of EBT (left) compared to MG (right) for the same patient diagnosed as normal case. 


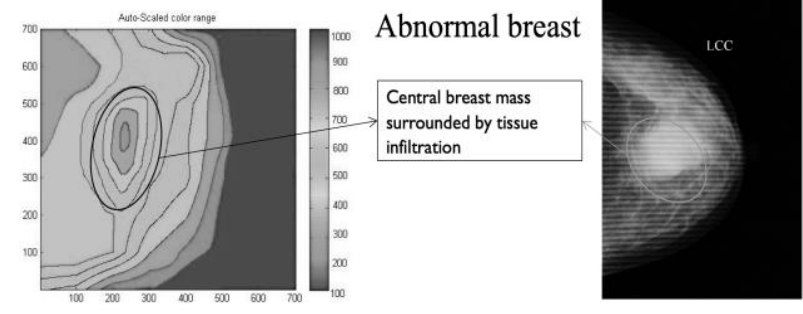

Fig. 5. Images of EBT (left) compared to MG (right) for the same patient diagnosed as abnormal case.

The sensitivity of EBT in diagnosing different breast pathology was found to be less sensitive compared to mammography. Details of the sensitivity analysis are shown in Table 1. The results of study showed that, no significant difference in sensitivity between mammography and EBT $(\mathrm{p}=0.696)$.

Table -1 Comparative sensitivity results for MG and EBT

\begin{tabular}{|c|c|c|c|}
\hline \multirow{2}{*}{ Diagnosis } & \multirow{2}{*}{ No. of Cases } & \multicolumn{2}{|c|}{ Sensitivity } \\
\cline { 3 - 4 } & & $\begin{array}{c}\text { X-ray } \\
\text { Mammography }\end{array}$ & $\begin{array}{c}\text { Electrical } \\
\text { Bioimpedance }\end{array}$ \\
\hline Normal & $\mathbf{5 4}$ & $\mathbf{7 4 \%}$ & $\mathbf{7 6 . 3 \%}$ \\
\hline Benign & $\mathbf{2 4}$ & $\mathbf{8 6 . 4}$ & $\mathbf{7 3 . 2}$ \\
\hline Malignant & $\mathbf{4 8}$ & $\mathbf{9 8 . 8 \%}$ & $\mathbf{8 1 . 6 \%}$ \\
\hline
\end{tabular}

In 2012, Raneta et al. (2012) conducted a study among 808 patients on women from Slovakia found that the sensitivity of EBT was $87 \%$, lower than MG (89\%), but these differences is insignificant. The findings of this study showed that, in combinations EIT + MG sensitivity increased to 96\% [23].

Zain et al. (2014) [24] did one study among 150 symptomatic women underwent EBT examination in Department of Radiology, University of Kebangsaan Malaysia Medical Center, Malaysia. Results of this study showed EBT had $64.4 \%$ of sensitivity using diagnostic (MG).

\section{CONCLUSION}

With EBT imaging, there two most important factors that affect EBT sensitivity, careful electrode plate positioning and the patient's remaining motionless during imaging procedure.

In conclusion, based on the results of this study and the obtained from previous studies related to sensitivity of EBT and comparing with MG; it appropriate to use EBT for preventive check-ups of the female population between rounds of screening in order to isolate patients at risk; in examination of pregnant and lactating women and with younger age women as well as women with high risk factors of cancer and as an additional method.

\section{REFERENCES}

[1] Hirko, K., Soliman, A., Hablas, A., Sefeldin, I. Ramadan, M., Banerjee, M., Harford, Joe, Chamberlain, R., and Merajver, S., (2013), Trends in Breast Cancer Incidence
Rates by Age and Stage at Diagnosis in Gharbiah, Egypt, over 10 Years (1999-2008), Journal of Cancer Epidemiology, volume 2013 (pp. 1-7).

[2] Kulakci, H., Yildirim, N., Topan, and Aysel Kose, (2015), Effects of breast cancer fatalism on breast cancer awareness among nursing students in Turkey. Asian Pac J Cancer Prev, 16(8), (pp. 3565-3572).

[3] Che, CC, Coomarasamy, J., and Suppayah, DB, (2014), Perception of breast health among malaysian female adolescents. Asian Pac J Cancer Prev, 15 (9), (pp. 71757180 .

[4] World Health Organization (2009), Breast cancer: prevention and control [Online].

[5] Stojadinovic, A, Nissan, A, Gallimidi, Z, Lenington S, Logan W, Zuley, M, Yeshaya, A, Shimonov, M, Fields, S, Allweis, T, Ginor, R, Gur, D, and Shriver, CD, (2005), Electrical impedance scanning for the early detection of breast cancer in young women: Preliminary results of a multicenter prospective clinical trial. J Clin Oncol., 23(12), (pp. 2703-2715).

[6] Malaysia - Penninsular, Cancer Statistics Report (2006), National Cancer Registry, Ministry of Health (Malaysia). Kuala Lampur, Malaysia.

[7] Martin, G, Martin, R, Brieva, MJ, and Santamaria, L. (2002), Electrical impedance scanning in breast cancer imaging: Correlation with mammographic and histologic diagnosis. Eur Radiol., 12(6), (pp. 1471-1478).

[8] Vithana, CH, Ariyaratne, MAY, and Jayawardana, PL. (2015), Effectiveness of an educational intervention among public health midwives on breast cancer early detection in the district of gampaha, sri lanka. Asian Pac J Cancer Prev, 16, (pp. 227-232).

[9] Breast Cancer Detection Demonstration Project (BCDDP), (1985), J. Reproductive Medicine, 30:45 (1-459).

[10] Kopans, and Daniel, B. (1998), Breast Imagine 2nd Edition, Lippincott-Raven Publishers, Philadelphia, 142.

[11] Biren, A. Shah, Gina, M. Fundaro, Sabala, and Mandava. (2010), Breast Imaging Review: A Quick guide to essential diagnosis. Springer Science+Business Media Publishers, New York, Heidelberg, Dordrecht, London, LLC, (2-78).

[12] Whitley, A. Stewart, Sloane, Charles , Hoadley, Graham, Moore, Adrian, and Alsop, Chrissie, (2005), Clark's positioning in radiography, section 15 mammography, 12th edition, (pp. 436-452).

[13] Chakraborti, KL, and Selvamurthy, W., (2010), Clinical application of electrical impedance tomography in the present health scenario of India. J Phys Conf Ser, 224, 12069.

[14] Kinouchi, Y, Pandya, AS, Arimoto, A, and Agarwal, A., (2002) A novel approach for measuring electrical impedance tomography for local tissue with artificial 


\section{International Journal of Engineering Applied Sciences and Technology, 2020 \\ Vol. 4, Issue 10, ISSN No. 2455-2143, Pages 1-4 \\ Published Online February 2020 in IJEAST (http://www.ijeast.com)}

intelligent algorithm. International $\mathrm{J}$ Biometrics Bioinformatics, 3, (pp. 66-81).

[15] Martin, G, Martin, R, Brieva, MJ, and Santamaria, L., (2002), Electrical impedance scanning in breast cancer imaging: correlation with mammographic and histologic diagnosis. Eur Radiol, 12, (pp. 1471-1478).

[16] Zou, Y, and Guo, Z., (2003), A review of electrical impedance techniques for breast cancer detection. Med Eng Phys, 25, (pp. 79-90).

[17] Malich, A, Boehm, T, Facius, M, Freesmeyer, MG, Fleck, M, Anderson, R, and Kaiser, WA., (2001), Differentiation of mammographically suspicious lesions: evaluation of breast ultrasound, MRI mammography and electrical impedance scanning as adjunctive technologies in breast cancer detection. Clin Radiol, 56, (pp. 278-283).

[18] Prasad, SN, Houserkova, D, and Campbell, J., (2008), Breast imaging using 3D electrical impedance tomography. Biomed Pap Med Fac Univ Palacky Olomouc Czech Repub, 152, (pp. 151-154).

[19] Cherepenin, V, Karpov, A, Korjenevsky, A, Kornienko, VN, Mazaletskaya, A, Mazourov, D, and Meister, D, (2001),. A 3D electrical impedance tomography (EIT) system for breast cancer detection. Physiol Meas, 22, (pp. 9-18)

[20] Cherepenin, V, Karpov, A, Korjenevsky, A, Kornienko, VN, Kultiasov, VS, Ochapkin, MB, Trochanova, OV, and Meister, JD, (2002), Three-dimensional EIT imaging of breast tissues: System design and clinical testing. IEEE Trans Med Imag, 21, (pp. 662-667).

[21] Athanasiou, A, Vanel, D, Fournier, L, and Balleyguier, C, (2007), Optical mammography: A new technique for visualizing breast lesions in women presenting non palpable BIRADS 4-5 imaging fi ndings: preliminary results with radiologic-pathologic correlation. Cancer Imaging, 7, (pp. 34-40).

[22] Gary, A, Ybarra, Qing H., Liu, Gang Ye, Kim, H. Lim, Joon-Ho, Lee, William, T. Joines, and Rhett, and T. George. (2007), Breast Imaging using Electrical Impedance Tomography (EIT), American Scientific Publishers, Chapter 15, (pp. 1-16).

[23] Renata, O, Ondrus, D, and Bella, V., (2012), Utilisation of electrical impedance tomography in breast cancer diagnosis. Clin Oncol, 25, (pp. 36-41).

[24] Zain, NM, and Chelliah, KK., (2014a), Breast imaging using electrical impedance tomography: correlation of quantitative assessment with visual interpretation. Asian Pac J Cancer Prev, 15, (pp.1327-1331). 